\title{
Curcumin induces apoptosis of triple-negative breast cancer cells by inhibition of EGFR expression
}

\author{
XIAO-DONG SUN ${ }^{1}$, XING-E LIU ${ }^{2}$ and DONG-SHENG HUANG ${ }^{1}$ \\ ${ }^{1}$ Department of Hepatobiliary and Pancreatic Surgery, Zhejiang Provincial People's Hospital, Hangzhou, Zhejiang 310014; \\ ${ }^{2}$ Department of Medical Oncology, Zhejiang Hospital, Hangzhou, Zhejiang 310013, P.R. China
}

Received May 28, 2012; Accepted September 14, 2012

DOI: $10.3892 / \mathrm{mmr} .2012 .1103$

\begin{abstract}
Curcumin is the major component of the spice turmeric, extracted from the rhizomes of the plant Curcuma longa. It exerts a number of therapeutic effects, including the inhibition of cancer cell proliferation. However, the anti-carcinogenic mechanism of curcumin has not been fully elucidated. Triple-negative breast cancer (TNBC), which lacks expression of the estrogen receptor (ER), progesterone receptor (PR) and epidermal growth factor receptor 2 (HER2/EGFR2), is an aggressive breast cancer phenotype with a poor prognosis. In this study, we investigated the effects of curcumin on triple-negative breast cancer cells and the possible molecular mechanisms. The MDA-MB-231 TNBC cells were treated with curcumin, the growth inhibition ratio of the cells was measured by MTT assay, apoptosis was detected by flow cytometry and the expression levels of extracellular regulated protein kinase (ERK1/2), pERK1/2,EGFR and pEGFR were detected by western blotting. After treatment with different concentrations of curcumin, the growth inhibition rates of the MDA-MB-231 breast cancer cells of the $30 \mu \mathrm{mol} / \mathrm{ml}$ curcumin-treated group were significantly different from those of the other groups. The level of apoptosis of the curcumin-treated group $(26.34 \%)$ was significantly different from that of the control group (2.76\%). The expression levels of pERK1/2 and pEGFR in the curcumin-treated group were significantly decreased compared with those of the control group. These results indicate that curcumin is able to inhibit the proliferation of TNBC cells. Inhibition of the EGFR signaling pathway is the likely underlying molecular mechanism.
\end{abstract}

\section{Introduction}

Curcumin is a natural yellow-pigmented polyphenol component of the spice turmeric, which is derived from the roots of the Curcuma longa plant which is indigenous to Southeast Asia. Curcumin has potent antioxidant, anti-mutagenic and antitumor properties. In recent years, studies have shown that

Correspondence to: Dr Xing-E Liu, Department of Medical Oncology, Zhejiang Hospital, Hangzhou, Zhejiang 310013, P.R. China E-mail: xingel@sohu.com

Key words: curcumin, EGFR, breast cancer, triple negative curcumin is able to inhibit the growth, invasion and metastasis of a variety of tumor cells, induce apoptosis through a variety of mechanisms and increase the sensitivity of tumor cells to chemotherapeutic drugs and radiation $(1,2)$.

Breast cancer is the most common malignant disease among women worldwide. Triple-negative breast cancer (TNBC), which represents approximately $15 \%$ of all breast cancers (3) and shows high recurrence and poor survival rates (4), is defined by the lack of estrogen receptor (ER), progesterone receptor (PR) and epidermal growth factor receptor 2 (HER2/cerbB2/ EGFR2) expression (5). Thus, to date, TNBC lacks effective targeted therapies. Endocrine therapy is also ineffective. Chemotherapy remains the only possible therapeutic option in the adjuvant or metastatic setting, but TNBC is frequently resistant to standard chemotherapeutic regimens. Therefore, TNBC has the worst prognosis of all breast cancer subtypes. TNBC cells are often accompanied by high expression levels of EGFR and abnormal activation of MAPK signaling pathways $(6,7)$. However, it has not been reported whether curcumin is able to inhibit the proliferation of TNBC cells and induce apoptosis through the inhibition of EGFR-MAPK signaling pathways. In this study, we studied the effects of curcumin on TNBC cells and the possible mechanism.

\section{Materials and methods}

Materials and reagents. The MDA-MB-231 (ER-/PR-/HER2$\mathrm{EGFR}^{+}$) breast cancer cells were purchased from the Shanghai Cell Bank of the Chinese Academy of Sciences (Shanghai, China). The study was approved by the ethics committee of Zhejiang Provincial People's Hospital, Hangzhou, China. Curcumin was purchased from Sigma (St. Louis, MO, USA). Rabbit anti-human ERK1/2, pERK1/2 antibody and rabbit antihuman EGFR, pEGFR antibody products were obtained from Cell Signaling Technology (Danvers, MA, USA) and mouse anti-rabbit secondary antibody was purchased from Beijing Zhongshan Golden Bridge Biotechnology Co., Ltd. (Beijing, China). The Annexin V/PI apoptosis detection kit was purchased from United Biotechnology Co., Ltd. (Shanghai, China) and DMEM and fetal bovine serum were acquired from Gibco-BRL (Carlsbad, CA, USA). MTT was purchased from Sigma.

MTT assay of breast cancer cell proliferation. To detect the rate of cell proliferation, MDA-MB-231 cells in DMEM 
Table I. Growth inhibition rates of MDA-MB-231 cells detected by MTT $(\%$, mean \pm SD).

\section{Group}

Control

Curcumin treatment
$(10 \mu \mathrm{mol} / \mathrm{ml})$
$14.67 \pm 3.26$
$(20 \mu \mathrm{mol} / \mathrm{ml})$
$18.53 \pm 3.59$
$(30 \mu \mathrm{mol} / \mathrm{ml})^{\mathrm{a}}$
$58.76 \pm 4.97$

${ }^{\mathrm{a}} \mathrm{P}<0.01$ vs. other groups (T-test).

Table II. Apoptosis rate of MDA-MB-231 cells detected by flow cytometery $(\%$, mean $\pm \mathrm{SD})$.

Group

Control

MDA-MB-231 cells

Curcumin treatment

$(10 \mu \mathrm{mol} / \mathrm{ml})$

$(20 \mu \mathrm{mol} / \mathrm{ml})$

$(30 \mu \mathrm{mol} / \mathrm{ml})^{\mathrm{a}}$

${ }^{\mathrm{a}} \mathrm{P}<0.01$ vs. other groups (T-test)

media containing $10 \%$ FBS with penicillin and streptomycin $(100 \mu / \mathrm{ml})$ were incubated at $37^{\circ} \mathrm{C}$ in a humidified atmosphere of $5 \% \mathrm{CO}_{2}$. After digestion with $0.25 \%$ trypsin, $1 \times 10^{4} / \mathrm{ml}$ cells were inoculated into 96 -well culture plates at $37^{\circ} \mathrm{C}$ overnight. The cells were divided into control and curcumin (10, 20 and $30 \mu \mathrm{mol} / \mathrm{ml}$ ) treatment groups and cultured in 96-well plates for $48 \mathrm{~h}$. The cells were then centrifuged for $3 \mathrm{~min}$ at $500 \mathrm{xg}$ and $100 \mu \mathrm{l}$ supernatant was removed. MTT $10 \mu \mathrm{l}(5 \mathrm{mg} / \mathrm{ml})$ was added, the cells were incubated for $4 \mathrm{~h}$ at $37^{\circ} \mathrm{C}$ and $100 \mu \mathrm{l}$ DMSO was added. After shocking for $10 \mathrm{~min}$, the OD490 value was detected using an enzyme immunoassay instrument. The rate of inhibition of cell proliferation was calculated as follows: inhibition rate $=\left(1-\mathrm{A}_{\text {treatment group }} / \mathrm{A}_{\text {control group }}\right) \times 100 \%$.

Curcumin-induced apoptosis of breast cancer cells. An Annexin V-FITC/PI double staining method was carried out according to the kit's instructions: MDA-MB-231 cells were routinely cultured with DMEM. After digestion with $0.25 \%$ trypsin, $1 \times 10^{5} / \mathrm{ml}$ cells were inoculated into 6 -well culture plates at $37^{\circ} \mathrm{C}$ overnight. The cells were divided into control and curcumin $(10,20$ and $30 \mu \mathrm{mol} / \mathrm{ml})$ treatment groups. After a 48-h treatment, the cells were collected following trypsin digestion, centrifuged for $5 \mathrm{~min}$ at $800 \mathrm{x} \mathrm{g}$ and then washed three times with PBS. Buffer $(50 \mu \mathrm{l})$ was added followed by V-FITC (5 $\mu \mathrm{l})$ and PI $(10 \mu \mathrm{l})$. The cells were incubated in the dark for $>5$ min and then evaluated by flow cytometry.

Effect of curcumin on EGFR and ERK1/2 phosphorylation. The expression levels of ERK1/2, pERK1/2, EGFR and pEGFR were detected by western blot analysis. MDA-MB-231 cells were cultured with DMEM. After digestion with $0.25 \%$ trypsin, $1 \times 10^{5} / \mathrm{ml}$ cells were inoculated into 6 -well culture plates at $37^{\circ} \mathrm{C}$ overnight. The cells were divided into control and curcumin $(30 \mu \mathrm{mol} / \mathrm{ml})$ treatment groups; $48 \mathrm{~h}$ later, the cells were collected, subjected to one-step cleavage and after 13,000 rpm high-speed centrifugation for $10 \mathrm{~min}$, the supernatant was taken for protein quantification. The $10 \%$ SDS-PAGE separating gel and laminated gel were prepared conventionally. Cells in the above groups were collected separately, and total proteins in each group were extracted using the one-shot method. After mixing with $4 \mathrm{X}$ loading buffer, boiling for $5 \mathrm{~min}$ and centrifuging at $12000 \mathrm{rpm}$ for $3 \mathrm{~min}, 20 \mu \mathrm{l}$ of the resulting sample was used for SDS-PAGE analysis at $100 \mathrm{~V}$. The gel was gently removed, washed once with Millipore $\mathrm{H}_{2} \mathrm{O}$ and electrophoretically transferred to a membrane at $100 \mathrm{~V}$ for $2 \mathrm{~h}$. After blocking with a blocking buffer at $37^{\circ} \mathrm{C}$ for $2 \mathrm{~h}$, the membrane was incubated with the corresponding primary antibody $(1: 1,000)$ overnight at $4^{\circ} \mathrm{C}$, washed with TBST four times at 10-min intervals and then incubated with the corresponding horseradish peroxidaselabeled secondary antibody $(1: 5,000)$ at room temperature for $1 \mathrm{~h}$. After washing with TBST 4 times at 10-min intervals, an ECL reagent was added and the results were detected using an X-ray film. With GAPDH as an internal control, the gray scales of the bands were analyzed semi-quantitatively using Band Leader software.

Statistical analysis. SPSS 13.0 software was used for statistical analysis, all data are shown as the mean \pm SD. Statistical differences were determined by $\mathrm{t}$-test analysis and $\mathrm{P}<0.05$ was considered to indicate a statistically significant result.

\section{Results}

Cell proliferation inhibition rate detected by MTT assay. The results showed that as the curcumin concentration increased its inhibitory effect on MDA-MB-231 cell proliferation also increased; at a concentration of $30 \mu \mathrm{mol} / \mathrm{ml}$, the proliferation inhibiting effect of curcumin on the MDA-MB-231 cells was significantly higher than that of the other groups $(\mathrm{P}<0.01$; Table I).

Apoptosis detected by flow cytometry. The curcumin-induced effects on MDA-MB-231 cell apoptosis were determined by flow cytometry. The apoptosis rates of the control and $30 \mu \mathrm{mol} / \mathrm{ml}$ curcumin treatment groups were 2.76 and $26.34 \%$, respectively; these results were significantly different $(\mathrm{P}<0.01$; Table II; Fig. 1).

EGFR and ERK1/2 phosphorylation levels in MDA-MB-231 cells inhibited by curcumin. Using GAPDH as internal control, the results were obtained by semi-quantitative analysis of the gray scales of the bands using Band Leader software. The results revealed that the expression level of EGFR in the curcumin treatment group was not significantly different from that in the control group $(\mathrm{t}=7.91, \mathrm{P}=0.92)$ while the expression level of $\mathrm{pEGFR}$ in the curcumin treatment group was significantly decreased compared with that in the control group $(\mathrm{t}=10.59, \mathrm{P}<0.001)$. The expression level of ERK1/2 in the curcumin treatment group was not significantly different from that in the control group $(\mathrm{t}=0.06, \mathrm{P}=0.95)$, 

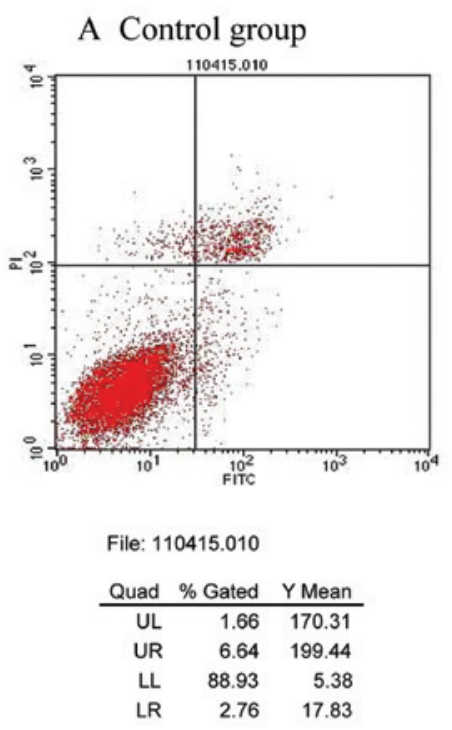

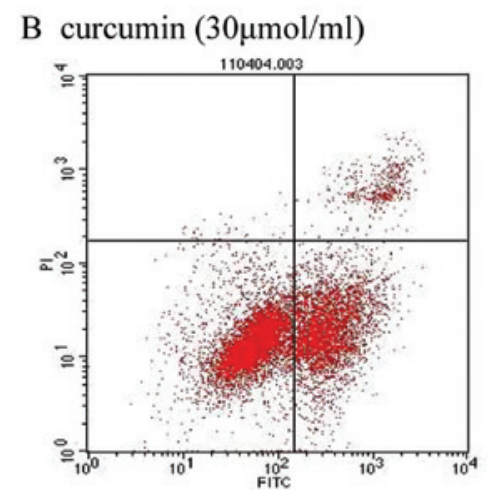

File: 110404.003

\begin{tabular}{crr} 
Quad & $\%$ Gated & Y Mean \\
\hline UL & 0.36 & 240.26 \\
UR & 4.06 & 716.09 \\
LL & 60.28 & 17.28 \\
LR & 35.29 & 25.94
\end{tabular}

Figure 1. Apoptosis rates of MDA-MB-231 cells (\%).

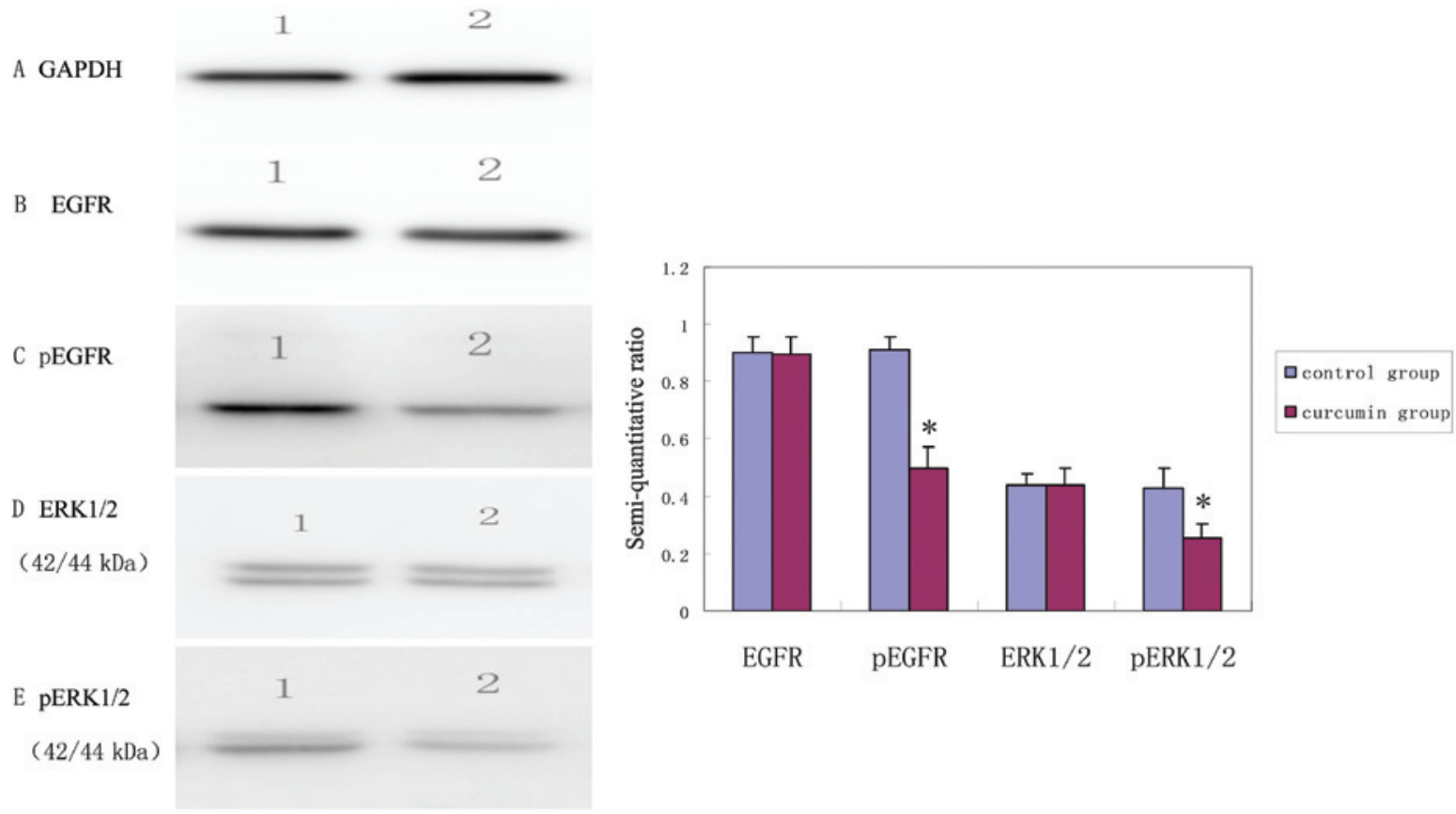

Figure 2. Expression levels of EGFR, pEGFR, ERK1/2 and pERK1/2 detected by western blot analysis. Expression levels of (A) internal control GAPDH, (B) EGFR; (C) pEGFR; (D) ERK1/2 and (E) pERK1/2. Lane 1, control group, lane 2, curcumin treatment group (30 $\mu \mathrm{mol} / \mathrm{ml})$. EGFR, epidermal growth factor receptor; ERK, extracellular regulated protein kinase. ${ }^{*}<0.01$ vs. the control group (mean $\left.\pm S D, n=5\right)$.

while the expression level of pERK1/2 in the curcumin treatment group was significantly decreased compared with that in control group $(\mathrm{t}=4.80, \mathrm{P}=0.002)$. The results indicated that, after curcumin treatment for $48 \mathrm{~h}$, the expression levels of pEGFR and pERK1/2 in the MDA-MB-231 cells were decreased, suggesting that curcumin inhibited the activation of EGFR and its downstream signaling molecules (Fig. 2).

\section{Discussion}

Curcumin has a variety of therapeutic properties, including antioxidant, analgesic, anti-inflammatory, anti-proliferative and antiseptic activities (8). Curcumin has been well-studied as a potential anticancer agent for the past decade (1). It has been shown that curcumin prevents tumor initiation, proliferation and metastasis in breast, colon, oral, ovarian and a number of other human cancers (9). Numerous studies have confirmed that curcumin is able to inhibit the growth of various tumor cell lines and induce tumor cell apoptosis. Multiple mechanisms of action have been proposed, including inhibition of NF- $\mathrm{kB}$ and STAT3 transcription factor activities, regulation of tumor suppressor genes, cancer genes and their protein expression, induction of cell cycle arrest and regulation of apoptosis signaling $(10,11)$. Curcumin is able to reduce the activation levels of NF- $\mathrm{\kappa B}$ in 
KCP-4 and MDA-MB-231 cells, and suppress the expression levels of Bcl-2, Bcl-xL and survivin, which are apoptosis-related proteins regulated by NF- $\mathrm{kB}$ (12-14). The effect of curcumin on human cancer cell lines is multi-functional and the inhibition of telomerase expression followed by induction of apoptosis may be one of the major mechanisms by which curcumin inhibits the proliferation of cancer cells (15). Recent studies have shown that curcumin inhibits the EGFR, Her-2, Hh/Gli, Wnt/B-catenin and Notch signaling pathways $(16,17)$. Curcumin has been reported to potentiate the antitumor activity of gefitinib in cell lines and a xenograft mice model of NSCLC through inhibition of proliferation, EGFR phosphorylation and induction of EGFR ubiquitination and apoptosis (18). Curcumin has also been shown to reduce EGFR mRNA transcription and protein expression, thus inhibiting the proliferation of bladder cancer cells (19).

In our study, we found that when MDA-MB-231 TNBC cells were cocultured with gradually increasing concentrations of curcumin, the MDA-MB-231 cell proliferation activity gradually decreased; $30 \mu \mathrm{mol} / \mathrm{ml}$ curcumin significantly inhibited the MDA-MB-231 cell proliferation. The level of apoptosis in the curcumin-treated group was significantly different from that in the control group. The results indicate that curcumin is able to induce MDA-MB-231 cell apoptosis and inhibit cell proliferation in vitro. The expression levels of pERK1/2 and pEGFR in the curcumin-treated group were lower than those in the control group. The EGFR is highly expressed in approximately $60 \%$ of TNBCs (3). MAPK and PI3K-AKT signaling pathways were over-activated, suggesting that TNBC cell growth depends on the EGFR signaling pathway (20). High intratumoral EGFR and CK5/6 expression levels may have a role in the development of nodal or distant metastases in TNBC and may be predictive of metastatic disease (21). An EGFR inhibitor has been reported to induce a change from the mesenchymal to the epithelial phenotype in TNBC cells; the EGFR tyrosine kinase inhibitor erlotinib inhibited tumor growth and metastasis in a SUM149 xenograft mouse model (22). Our study identified that curcumin was able to inhibit EGFR and extracellular regulated protein kinase (ERK1/2) phosphorylation in MDA-MB-231 cells; ERK1/2 is one of the major signaling molecules downstream of EGFR. This suggests that curcumin inhibited the activation of EGFR and its downstream signaling molecules, thus inhibiting MDA-MB-231 cell proliferation. Anti-EGFR therapeutic strategies, including monoclonal antibodies (cetuximab, panitumumab) and small molecule inhibitors (gefitinib, erlotinib), may be of potential benefit in the treatment of TNBC (23).

Our result indicate that curcumin is able to inhibit the proliferation of MDA-MB-231 TNBC cells and induce their apoptosis in vitro by inhibiting the EGFR signaling pathway.

\section{References}

1. Goel A and Aggarwal BB: Curcumin, the golden spice from Indian saffron, is a chemosensitizer and radiosensitizer for tumors and chemoprotector and radioprotector for normal organs. Nutr Cancer 62: 919-930, 2010.

2. Basnet $\mathrm{P}$ and Skalko-Basnet N: Curcumin: an anti-inflammatory molecule from a curry spice on the path to cancer treatment. Molecules 16: 4567-4598, 2011.
3. Siziopikou KP, Ariga R, Proussaloglou KE, et al: The challenging estrogen receptor-negative/progesterone receptornegative/HER-2-negative patient: a promising candidate for epidermal growth factor receptor-targeted therapy? Breast J 12: 360-362, 2006

4. De Ruijter TC, Veeck J, de Hoon JP, et al: Characteristics of triple-negative breast cancer. J Cancer Res Clin Oncol 137: 183-192, 2011.

5. Thike AA, Cheok PY, Jara-Lazaro AR, et al: Triple-negative breast cancer: clinicopathological characteristics and relationship with basal-like breast cancer. Mod Pathol 23: 123-133, 2010.

6. Tan DS, Marchió C, Jones RL, et al: Triple negative breast cancer: molecular profiling and prognostic impact in adjuvant anthracycline-treated patients. Breast Cancer Res Treat 111: 27-44, 2008.

7. Eralp Y, Derin D, Ozluk Y, et al: MAPK overexprssion is associated with anthracycline resistance and increased risk for recurrence in patients with triple-negative breast cancer. Ann Oncol 19: 669-674, 2008

8. Wilken R, Veena MS, Wang MB and Srivatsan ES: Curcumin: a review of anti-cancer properties and therapeutic activity in head and neck squamous cell carcinoma. Mol Cancer 10: 12-31, 2011.

9. Reuter S, Eifes S, Dicato M, et al: Modulation of anti-apoptotic and survival pathways by curcumin as a strategy to induce apoptosis in cancer cells. Biochem Pharmacol 76: 1340-1351, 2008.

10. Kunnumakkara AB, Anand P and Aggarwal BB: Curcumin inhibits proliferation, invasion, angiogenesis and metastasis of different cancers through interaction with multiple cell signaling proteins. Cancer Lett 269: 199-225, 2008.

11. Rowe DL, Ozbay T, O'Regan RM and Nahta R: Modulation of the BRCA1 protein and induction of apoptosis in triple negative breast cancer cell lines by the polyphenolic compound curcumin. Breast Cancer (Auckland) 3: 61-75, 2009.

12. Oiso S, Ikeda R, Nakamura K, et al: Involvement of NF-кB activation in the cisplatin resistance of human epidermoid carcinoma KCP-4 cells. Oncol Rep 28: 27-32, 2012.

13. Chiu TL and Su CC: Curcumin inhibits proliferation and migration by increasing the $\mathrm{Bax}$ to $\mathrm{Bcl}-2$ ratio and decreasing NFKBp65 expression in breast cancer MDA-MB-231 cells. Int J Mol Med 23: 469-475, 2009.

14. Chakraborty G, Jain S, Kale S, et al: Curcumin suppresses breast tumor angiogenesis by abrogating osteopontin-induced VEGF expression. Mol Med Report 1: 641-646, 2008.

15. Cui SX, Qu XJ, Xie YY, et al: Curcumin inhibits telomerase activity in human cancer cell lines. Int J Mol Med 18: 227-231, 2006.

16. Mimeault M and Batra SK: Potential applications of curcumin and its novel synthetic analogs and nanotechnology-based formulations in cancer prevention and therapy. Chin Med 6: 31, 2011.

17. Hirose $\mathrm{H}$, Ishii $\mathrm{H}$, Mimori $\mathrm{K}$, et al: Notch pathway as candidate therapeutic target in Her2/Neu/ErbB2 receptor-negative breast tumors. Oncol Rep 23: 35-43, 2010.

18. Lee JY, Lee YM, Chang GC, et al: Curcumin induces EGFR degradation in lung adenocarcinoma and modulates p38 activation in intestine: the versatile adjuvant for gefitinib therapy. PLoS One 6: e23756, 2011.

19. Chadalapaka G, Jutooru I, Burghardt R and Safe S: Drugs that target specificity proteins downregulate epidermal growth factor receptor in bladder cancer cells. Mol Cancer Res 8: 739-750, 2010.

20. Billar JA, Dueck AC, Stucky CC, et al: Triple-negative breast cancers: unique clinical presentations and outcomes. Ann Surg Oncol 17 (Suppl 3): 384-390, 2010.

21. Sutton LM, Han JS, Molberg KH, et al: Intratumoral expression level of epidermal growth factor receptor and cytokeratin $5 / 6$ is significantly associated with nodal and distant metastases in patients with basal-like triple-negative breast carcinoma. Am J Clin Pathol 134: 782-787, 2010.

22. Ueno NT and Zhang D: Targeting EGFR in triple negative breast cancer. J Cancer 2: 324-328, 2011.

23. Sánchez-Muñoz A, Gallego E, de Luque V, et al: Lack of evidence for KRAS oncogenic mutations in triple-negative breast cancer. BMC Cancer 10: 136, 2010. 